\title{
脳動脈瘤に関する流体実験と数值解析による検討
}

\section{Analysis of cerebral aneurysm in fluid mock circuit and numerical calculation}

\author{
○ 村田 智幸（芝浦工業大学）正 藤本 哲男（芝浦工業大学） \\ 正 苗村 潔 （東京工科大学）
}

Tomoyuki MURATA, Shibaura Institute of Technology, Toyosu 3-7-5, Koto-ku, Tokyo

Tetsuo FUJIMOTO, Shibaura Institute of Technology,

Kiyoshi NAEMURA, Tokyo University of Technology, Katakurachou 1404-1, Hachioji-shi, Tokyo

\begin{abstract}
A cerebral aneurysm is circumscribed dilation of an intracranial artery and can be a cause of subarachnoidal hemorrhage which is a fatal disease when the aneurysm is ruptured. Some clinical data have suggested that the shape of the aneurysm affects the rupture. However, the relationship between the shape and the rupture has not been revealed. In this study, the hemodynamics in the aneurysm was computed in order to evaluate clinical data. As a result, the difference of dynamic effect in aneurysm was caused by difference of the shape of the aneurysm. Therefore, there is a possibility that shape of aneurysm and the rupture are related. In addition, it is necessary to make sure these results of numerical analysis by conducting some hydraulic experiments.
\end{abstract}

Key Words: cerebral aneurysm, aspect ratio, simulation

\section{1. 粕言}

脳動脈瘤（Fig. 1) は脳内の血管の一部が瘤状に肥大 する疾患で，万が一破裂した場合死亡率が高い。しか し破裂の原因が解明されていないため，破裂の予知は きわめて困難である. そのため未破裂脳動脈瘤の破裂 予防手術に関する指針作りが課題となっている.

Ujiie らは臨床調查より, 脳動脈瘤の形状特性から成 る AR(Aspect Ratio)（Fig. 2) から, 破裂を予知できる 可能性を提唱した ${ }^{2)}$. AR が増大するに伴い, 破裂した 瘤の割合も増加することが報告されている (Fig. 3) が， AR に基づくガイドライン制定には，工学的な説明が 不十分である。

本研究は, 脳動脈瘤および周辺血管の形状特性がも たらす瘤内部流れに着目し, 流れによる力学的影響と 脳動脈瘤破裂の可能性との関連を明らかにするため, 脳動脈瘤モデルを作製し数值流体解析を行った。

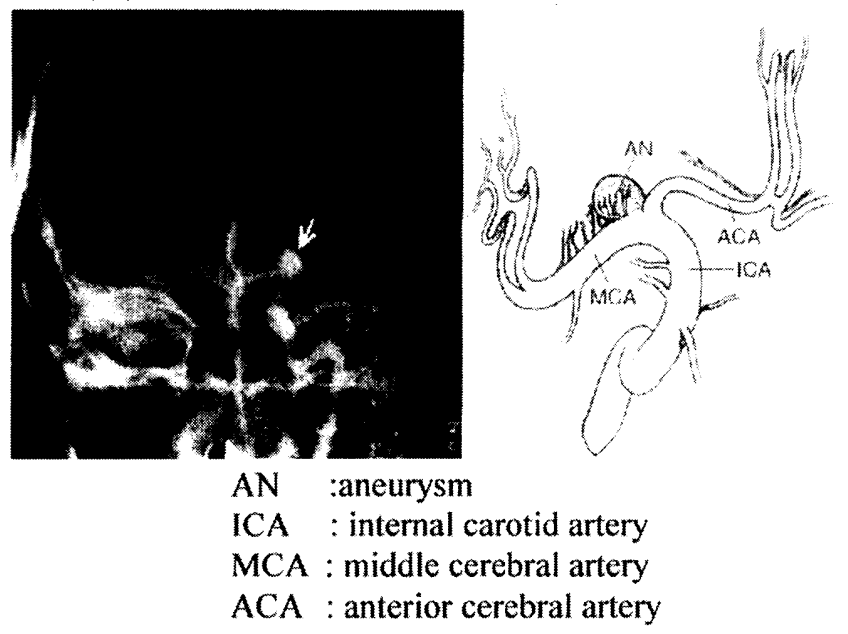

Fig. 1 Arteriogram of the frontal view of right side showing aneurysm ${ }^{1)}$

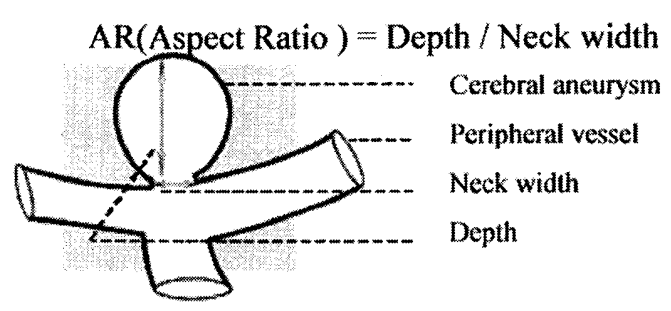

Fig. 2 Shape of cerebral aneurysm and aspect ratio

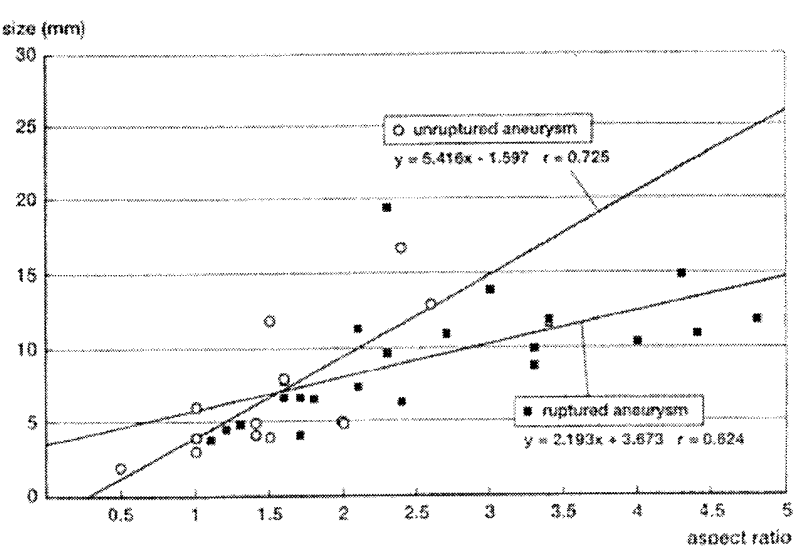

Fig. 3 Relationship between size and aspect ratio in the case of rupture or unrupture ${ }^{2)}$

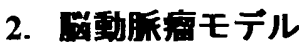

解析対象となる脳動脈瘤モデルは $\mathrm{Gambit}^{\circledR}$ を用いて 三次元形状を作製した（Fig. 4)。脳動脈瘤はウイリス 輪 (Circle of Willis) の血管分岐部に発生しやすいこと から ${ }^{3)}$, 周辺血管部を $Y$ 字型とし，瘤は血管分岐部に 作製した，主管入口から流入した流体は，主管と分岐 管のなす角 $\alpha=135^{\circ}$ で分岐し分肢管出口から流出する。 臨床調查結果 ${ }^{2)}$ より瘤直径 $D_{a}$ は 8,10,12mm の 3 種を適 用した。主管の直径は，ウイリス輪直前の内頸動脈直 径の平均值 ${ }^{4)}$ を想定し $d_{0}=5 \mathrm{~mm}$, 分岐管直径を $d_{I}=4 \mathrm{~mm}$, 
主管と分岐管の長さを $50 \mathrm{~mm}$ とした。

本解析は，左右分岐管へ流れ込む流体の流量比を変 化させるため分岐管直径 $d_{l}=4 \mathrm{~mm}$ 一定とするのに対し， $d_{2}=1,2,3 \mathrm{~mm}$ と変化させた（Table 1). さらに各瘤值径 のモデルごとに瘤内部流れを変化させるため, 瘤中心 の位置を, 主管中心軸に対し垂直方向に移動させた。

ここで, 移動変位を $l[\mathrm{~mm}]$ とした.

Table 1. Range of $d_{2}$ and displacement

\begin{tabular}{c|c|c|c}
\hline \hline$d_{2}$ & \multicolumn{3}{|c}{ displacement $l[\mathrm{~mm}]$} \\
\cline { 2 - 4 }$[\mathrm{mm}]$ & $D_{a}: 8 \mathrm{~mm}$ & $D_{a}: 10 \mathrm{~mm}$ & $D_{a}: 12 \mathrm{~mm}$ \\
\hline 1 & $-1.0 \sim 1.5$ & $-1.0 \sim 2.5$ & $-1.0 \sim 3.0$ \\
2 & $-1.5 \sim 1.5$ & $-2.5 \sim 2.5$ & $-3.0 \sim 3.0$ \\
3 & $-1.5 \sim 1.5$ & $-2.5 \sim 2.5$ & $-3.0 \sim 3.0$ \\
\hline
\end{tabular}

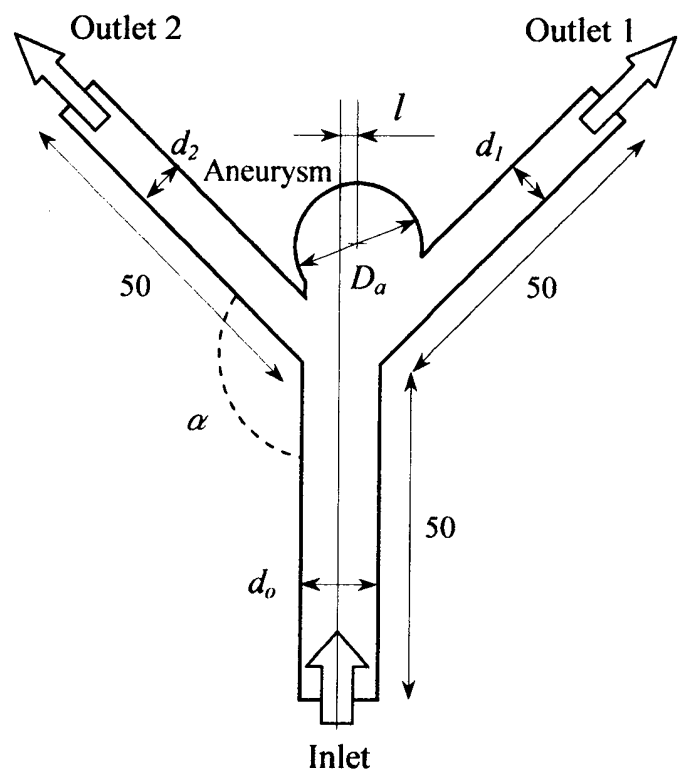

Fig. 4 Structure of cerebral aneurysm model

\section{3-1 韸散化手法}

\section{3. 数值解析}

本解析において作動流体を非圧縮性流体とし, 式(1), (2)に示す三次元の Navier-Stokes 方程式と連続の式を 用いた。

$$
\begin{aligned}
& \frac{\partial\left(\rho u_{i}\right)}{\partial t}=-\frac{\partial\left(\rho u_{j} u_{i}\right)}{\partial x_{j}}-\frac{\partial P}{\partial x_{i}}+\frac{\partial}{\partial x_{j}}\left[\mu\left(\frac{\partial u_{i}}{\partial x_{j}}+\frac{\partial u_{j}}{\partial x_{i}}\right)\right]+F i \\
& \frac{\partial u_{i}}{\partial x_{i}}=0
\end{aligned}
$$

ここで, $\rho$ は密度, $u$ は速度， $P$ は圧力， $F$ は外力で あり, 解析には有限体積法による流体解析ソフト FLUENT を用い, 定常解析を行った。離散化手法は二 次精度風上（Second-Order-Upwind）, 圧力補間手法は PREST!を用いた. また圧力一速度の連成手法は定常解 析に有効な SIMPLEを用いた。

\section{$3 \cdot 2$ 数值侽析条件}

作動流体の物性值は水を想定し, 密度 $998.2 \mathrm{~kg} / \mathrm{m}^{3}$, 粘度 $100.2 \times 10^{-5} \mathrm{~Pa} \cdot \mathrm{s}$ とした（Table 2)。ここで解析の 対象となる血管径及びせん断速度は十分大きいので作
動流体をニュートン流体とみなし, 壁面部の境界条件 はす心゙り無しとした．流入部の境界条件は，ヒトの血 行動態を想定して入口流速 $0.40 \mathrm{~m} / \mathrm{s}$ を与え, 流出部は 脳動脈部の血圧を考虑し出口圧力 $70 \mathrm{mmHg}$ を適用した。 計算格子は四面体要素で生成し,数值解析は計算が収 束するまで絽り返し行った。

Table 2. Fluid-analysis conditions

\begin{tabular}{c|c}
\hline \hline Flow Condition & Steady Flow \\
\hline Working Fluid & $998.2 \mathrm{~kg} / \mathrm{m}^{3}, 100.2 \times 10^{-5} \mathrm{~Pa} \cdot \mathrm{s}$ \\
\hline \multirow{2}{*}{ Boundary Conditions } & Inlet:0.40m/s \\
\cline { 2 - 2 } & Outlet:70mmHg \\
\hline \multirow{2}{*}{ Mesh Volumes } & Element Number:68541 \\
\cline { 2 - 2 } & Element Shape:Tetrahedrally \\
\hline Solution Algorithm & SIMPLE \\
\hline Discretization & Second-Order-Upwind,PREST! \\
\hline
\end{tabular}

\section{$3 \cdot 3$ 解析䊅果及び考察}

主管中心軸からの変位 $l$, および分岐管直径 $d_{2}$ を変 化させて得た瘤内最高圧力の変化を Fig. 5,6,7 に示す. この結果より, $l$ が大きい場合に瘤内最高圧力は高い值 を示し，この傾向は瘤直径が大きいほど顕著に現れる. また瘤直径の違いに関わらず，分岐管径 $d_{2}$ が小さいほ ぞ瘤内最高压力は高くなる。

これらは流れの違いによる力学的影響が関係すると 考えられる. 例えば瘤直径 $D_{a}=10 \mathrm{~mm}$, 分岐管径 $d_{2}=1 \mathrm{~mm}$ の場合, 流れの状態は大きく 4 種に分類できる. $D_{a}=10 \mathrm{~mm}, d_{2}=1 \mathrm{~mm}$ のモデルを流れる作動流体の速度 分布を Fig. 8,9,10,11 に示す.これより瘤内流れの分類 は，i 瘤内に流れがわずかに存在する流れ（Fig. 8), ii)瘤形状に沿って渦状に流れる流れ（Fig. 9)， iii)瘤壁 面に衝突する流れ（Fig. 10)， iv)主管からの流れが瘤 に直接衝突する流れ (Fig. 11) の 4 種類に分けられる.

ここで Fig. 6 および Fig. 11 より, 瘤直径 $D_{a}=10 \mathrm{~mm}$ では, 主管からの流れが, 直線的に直接瘤内に流れ込 む場合に瘤内最高圧力は最も高くなることがわかる。 同様に $D_{a}=12 \mathrm{~mm}$ の場合においても，流れの状態が iv) のときに瘤内最高圧力は最高値を示した。ささらに, $D_{a}=8 \mathrm{~mm}$ の場合には流れの状態が iv ) となる状況は存 在せず, 極端な圧力上昇は確認できない.

これらより，主管からの流れが瘤に直接衝突する場 合に瘤内圧力は最も高くなることから, 瘤および周辺 血管の形状特性がもたらす流れの力学的影響が，瘤破 裂の可能性に関連すると考えられる.

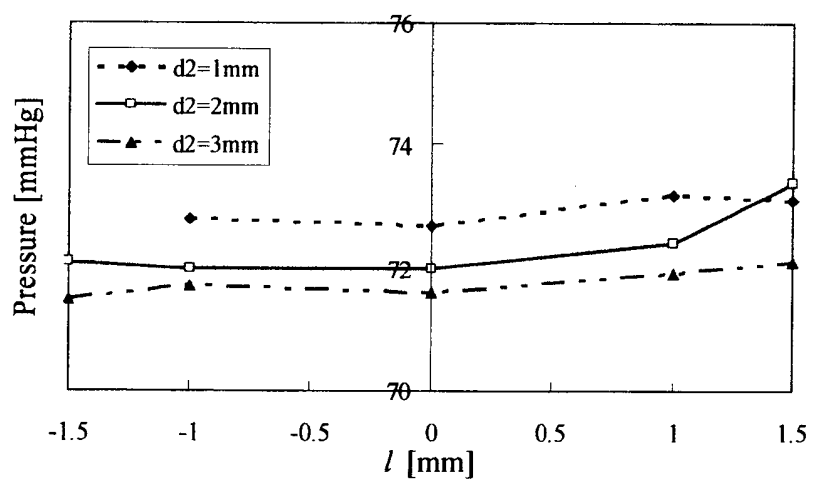

Fig. 5 Changes in pressure in the aneurysm during changes in the location of the aneurysm center $\left(D_{a}=8 \mathrm{~mm}\right)$ 


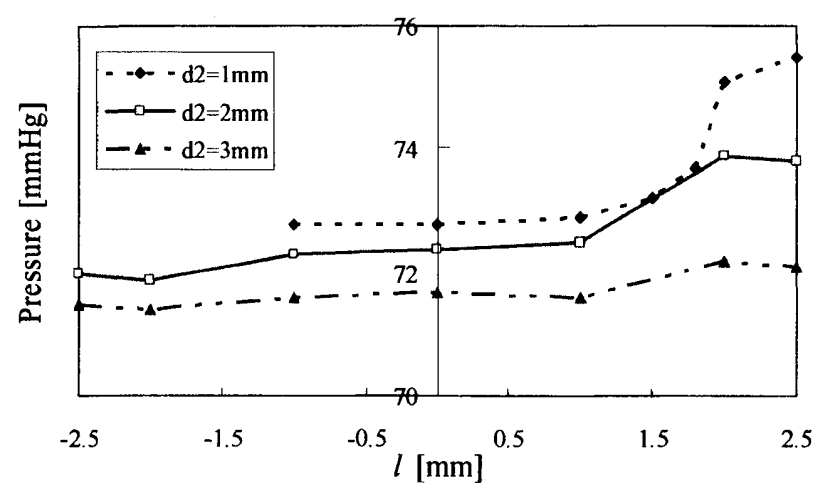

Fig. 6 Changes in pressure in the aneurysm during changes in the location of the aneurysm center $\left(D_{a}=10 \mathrm{~mm}\right)$

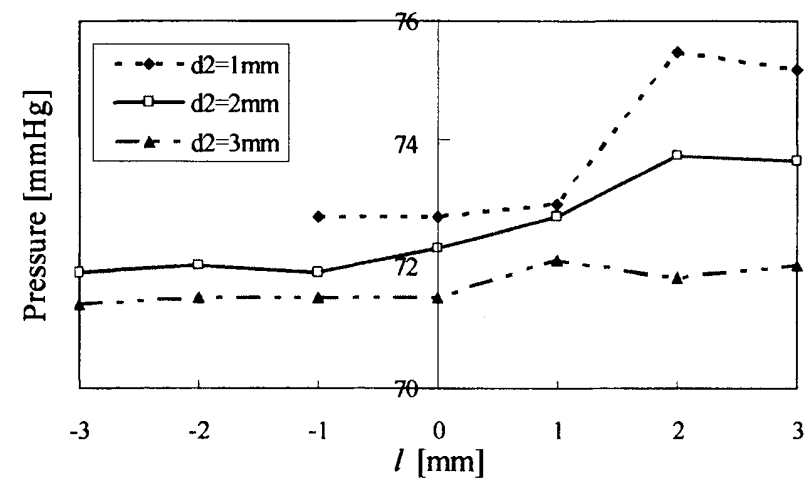

Fig. 7 Changes in pressure in the aneurysm during changes in the location of the aneurysm center $\left(D_{a}=12 \mathrm{~mm}\right)$

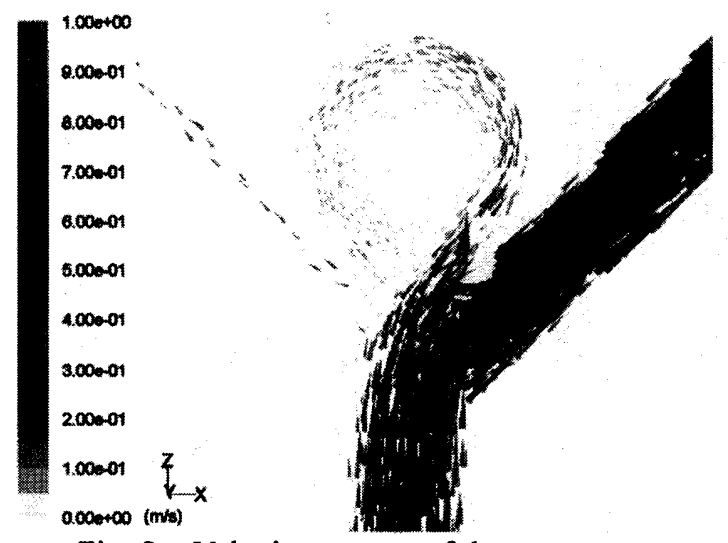

Fig. 8 Velocity vectors of the aneurysm $\left(D_{a}=10 \mathrm{~mm}, d_{2}=1 \mathrm{~mm}, l=0 \mathrm{~mm}\right)$
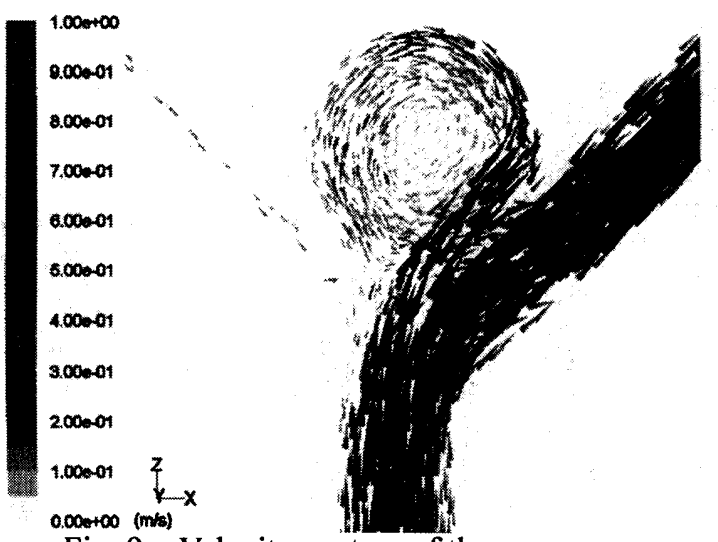

Fig. 9 Velocity vectors of the aneurysm $\left(D_{a}=10 \mathrm{~mm}, d_{2}=1 \mathrm{~mm}, l=1.0 \mathrm{~mm}\right)$
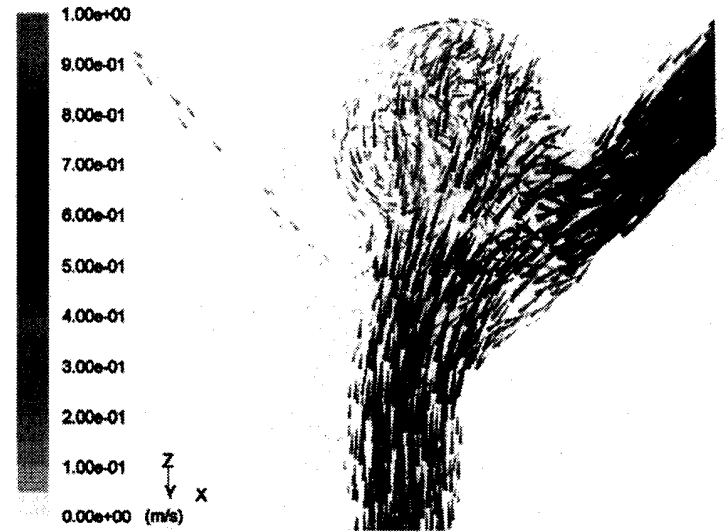

Fig. 10 Velocity vectors of the aneurysm ( $\left.D_{a}=10 \mathrm{~mm}, d_{2}=1 \mathrm{~mm}, l=1.8 \mathrm{~mm}\right)$

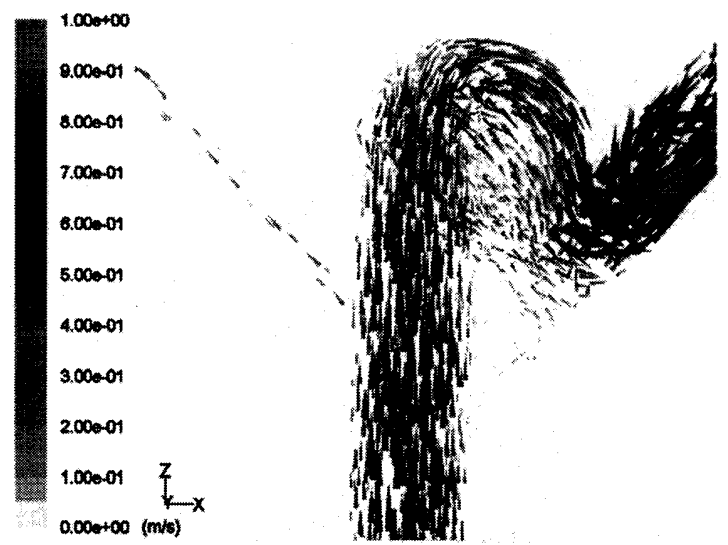

Fig. 11 Velocity vectors of the aneurysm $\left(D_{a}=10 \mathrm{~mm}, d_{2}=1 \mathrm{~mm}, l=2.5 \mathrm{~mm}\right)$

\section{4. 结言}

脳動脈瘤モデルの形状特性を変化させることにより 瘤内流れに変化が現れ, 瘤内最高圧力に違いが生じる ことが示された。これは左右分岐管径の差が大きいほ ど顕著に現れることが判明した．数值解析を通して， 流れの力学的影響が脳動脈瘤の破裂の原因に関わる可 能性が示されたといえる.

脳動脈瘤および周辺血管の形状特性から流れを分類, さらには特定させることが可能ならば，破裂の可能性 を予知する可能性があるといえる.

\section{参考文献}

1) Youmans JR, Neurological Surgery, (1996), 1293, W.B. Saunders Co., Philadelphia.

2) Hiroshi Ujiie M.D. et al., Is the Aspect Ratio a Reliable Index for Predicting the Rupture of a Saccular Aneurysm?, Neurosurgery,48-3(2001),495.

3) Mano J. Thubrikar, Vascular Mechanic And Pathology, (2007) Springer Co..

4) Weir B, Aneurysms Affecting the Nervous System, (1987), Williams \& Wilkins, Baltimore. 